10-1999

\title{
Toward Designing the Optimal Total Cavopulmonary Connection: an In Vitro Study
}

Ann E. Ensley

Georgia Institute of Technology

Patricia Lynch

Georgia Institute of Technology

Follow this and additional works at: https://engagedscholarship.csuohio.edu/encbe_facpub

orge $P$ Chatzimavroudis

Cleveland State University and Biomedical Optics Commons

How does access to this work benefit you? Let us know!

Par由/lisham's Statement

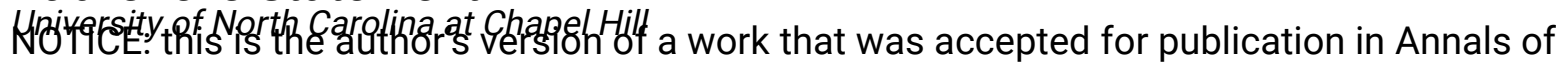

कhprasifapirgery. Changes resulting from the publishing process, such as peer review, editing,

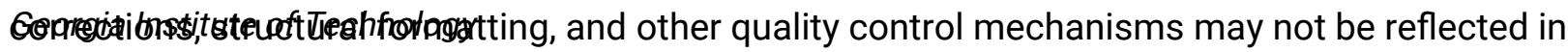
this document. Changes may have been made to this work since it was submitted for pee nextion. A definitive version was subsequently published in Annals of Thoracic Surgery, 68, 4, (October 1999) DOI 10.1016/S0003-4975(99)00560-3

\section{Original Citation}

Ensley AE, Lynch P, Chatzimavroudis GP, Lucas C, Sharma S, Yoganathan AP. Toward designing the optimal total cavopulmonary connection: an in vitro study. Ann Thorac Surg. 1999;68:1384-1390.

\section{Repository Citation}

Ensley, Ann E.; Lynch, Patricia; Chatzimavroudis, George P.; Lucas, Carol; Sharma, Shiva; and Yoganathan, Ajit P., "Toward Designing the Optimal Total Cavopulmonary Connection: an In Vitro Study" (1999). Chemical \& Biomedical Engineering Faculty Publications. 104.

https://engagedscholarship.csuohio.edu/encbe_facpub/104

This Article is brought to you for free and open access by the Chemical \& Biomedical Engineering Department at EngagedScholarship@CSU. It has been accepted for inclusion in Chemical \& Biomedical Engineering Faculty Publications by an authorized administrator of EngagedScholarship@CSU. For more information, please contact library.es@csuohio.edu. 


\section{Authors}

Ann E. Ensley, Patricia Lynch, George P. Chatzimavroudis, Carol Lucas, Shiva Sharma, and Ajit P. Yoganathan 


\title{
Toward Designing the Optimal Total Cavopulmonary Connection: An In Vitro Study
}

\author{
Ann E. Ensley, BS, Patricia Lynch, PhD, George P. Chatzimavroudis, PhD, \\ Carol Lucas, PhD, Shiva Sharma, MD, and Ajit P. Yoganathan, PhD
}

Schools of Biomedical and Chemical Engineering, Petit Institute for Bioengineering and Bioscience, Georgia Institute of Technology, Atlanta, Georgia, and Department of Biomedical Engineering, University of North Carolina at Chapel Hill, Chapel Hill, North Carolina

Background. Understanding the total cavopulmonary connection (TCPC) hemodynamics may lead to improved surgical procedures which result in a more efficient modified circulation. Reduced energy loss will translate to less work for the single ventricle and although univentricular physiology is complex, this improvement could contribute to improved postoperative outcomes. Therefore to conserve energy, one surgical goal is optimization of the TCPC geometry. In line with this goal, this study investigated whether addition of caval curvature or flaring at the connection conserves energy.

Methods. TCPC models were made varying the curvature of the caval inlet or by flaring the anastomosis. Steady flow pressure measurements were made to calculate the power loss attributed to each connection design over a range of pulmonary flow splits (70:30 to 30:70). Particle flow visualization was performed for each design and was qualitatively compared to the power losses.

Results. Results indicate that curving the cavae toward

$\mathrm{T}$ he total cavopulmonary connection (TCPC) is a modification of the original surgical repair of tricuspid atresia introduced by Francis Fontan [1] and is used for the management of single ventricle congenital heart disease. This procedure, which involves the anastomosis of the inferior (IVC) and superior vena cava (SVC) directly to the unbranched pulmonary artery (excluding most or all of the right atrium) has been the focus of recent studies in an attempt to reduce postoperative complications and improve functional outcome for patients.

Other researchers, including Lins and associates [2] and Laks and associates [3] proposed the idea of a unidirectional cavopulmonary connection where the SVC and IVC were connected exclusively to the left (LPA) and right pulmonary arteries (RPA), respectively. By having a fenestration in the inferior channel, this design would provide lower IVC pressure while matching the typically higher IVC flow to the larger right lung volume. Although this was an energetically favorable design idea, Srivastava and associates [4] later proposed the need for one pulmonary artery is advantageous only when the flow rate from that cavae matches the flow to the pulmonary artery. Under other pulmonary flow split conditions, the losses in the curved models are significant. In contrast, fully flaring the anastomosis reduced losses over the range of pulmonary flow splits. Power losses were $56 \%$ greater for the curving as compared to flaring. Fully flaring without caval offset reduced losses $45 \%$ when compared to previous models without flaring. If flaring on all sides was implemented with caval offset, power losses reduced $68 \%$ compared to the same nonflared model.

Conclusions. The results indicate that preferentially curving the cavae is only optimal under specific pulmonary flow conditions and may not be efficient in all clinical cases. Flaring of the anastomosis has great potential to conserve energy and should be considered in future TCPC procedures.

hepatic venous perfusion to both lungs to avoid the complication of pulmonary arteriovenous malformations (the so-called hepatic factor). If hepatic venous perfusion is necessary for the pulmonary circulation, the theoretical advantages of the unidirectional design may be negated.

Refocusing on the TCPC, with the above considerations in mind, this study specifically focused on the dissipative power losses associated with different connection types, and how in the surgical phase, those losses can be minimized. Energy conservation in Fontan patients' circulation may be very important considering there is only one functional ventricle to pump blood both to the systemic circulation and lungs. This increased work on the heart could be reduced if the efficiency of the modified connection is improved. Turning to the hemodynamics of the cavae to pulmonary artery anastomosis, our previous work [5] showed that collision of caval flows at the connection results in high dissipative energy losses and that introduction of offset between the caval inlets reduces those losses. Using computational fluid dynamics, de Leval and associates [6] also reported a decrease in dissipated power with an increase of at least $1.0 \mathrm{~cm}$ in caval offset. Therefore, in addition to offset, are there additional surgical measures that would ensure a more efficient connection? Previous computational models also 


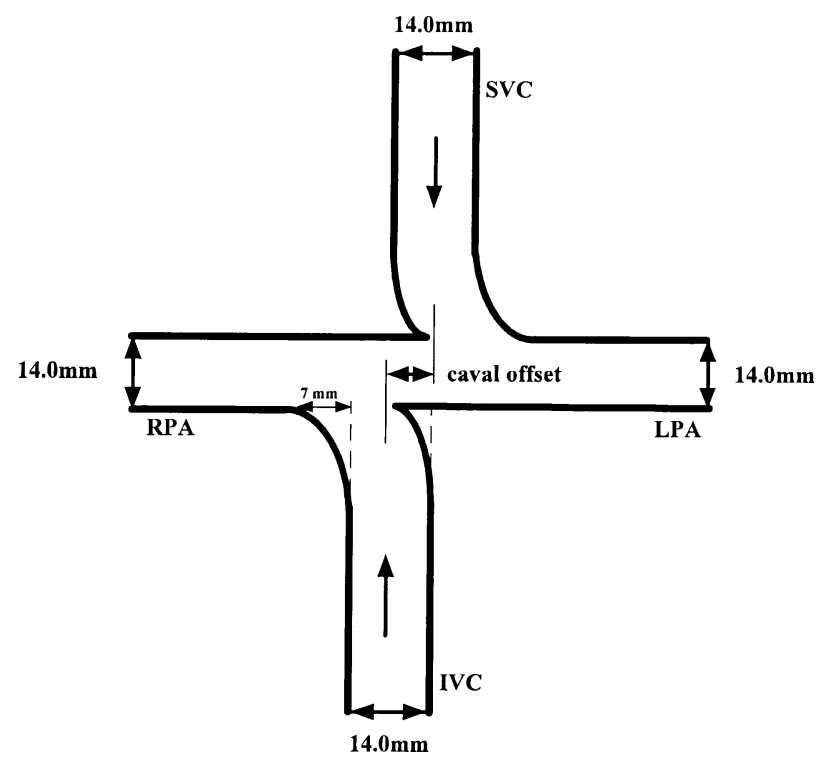

Fig 1. Curved TCPC model with a 0.5 diameter caval offset.

suggest that enlarging the IVC anastomosis reduces head loss [6]. The aim of the present study was to investigate whether the addition of preferential cavae to pulmonary artery (PA) curvature or flaring at the IVC and SVC connection sites conserves any additional amounts of energy.

\section{Material and Methods}

Glass models of a TCPC were custom-crafted, varying the geometry of the cavopulmonary anastomosis. A total of 9 models were studied to investigate the effects of curvature or flaring at the TCPC on the efficiency of the new geometry.

\section{Curved Models}

Figure 1 is a schematic of one curved model. The inner diameter of both cavae and pulmonary arteries was $14 \mathrm{~mm}$. The IVC was curved towards the RPA by attaching both the medial and lateral wall of the IVC each $7 \mathrm{~mm}$ (or $1 / 2$ diameter) to the right of normal incidence. The SVC was curved toward the LPA using the same method. This produced an effective radius of curvature of approximately $15 \mathrm{~mm}$. Four models were constructed with varying caval offsets of $0 \mathrm{~mm}$ (0.0-diameter offset), $7 \mathrm{~mm}$ (0.5-diameter offset), $14 \mathrm{~mm}$ (1.0-diameter offset) and $21 \mathrm{~mm}$ (1.5-diameter offset). Offset was defined as the horizontal distance between the caval midpoints.

\section{Flared Models}

Figure 2 is a schematic of the 5 flared models. In designs $1-4$, the radius of curvature of the flaring was approximately $10 \mathrm{~mm}$ whereas in design 5 there was less curvature (radius of curvature approximately $5 \mathrm{~mm}$ ). Design 1 incorporated flaring on all sides of the anastomosis in addition to a 0.0-diameter offset. Designs 2-5 had a 1.0-diameter caval offset with flaring located at different sides of the anastomosis (ie, A, B, C, and D in Fig 2). Designs 2 and 5 were flared at sites B and D (but with

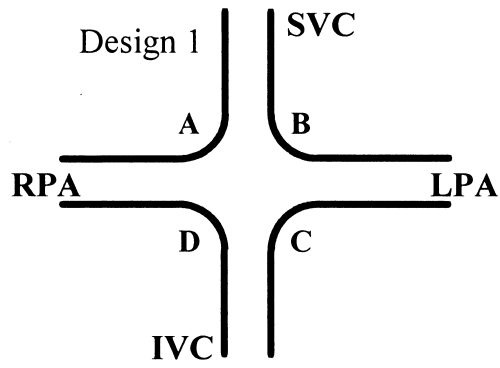

A

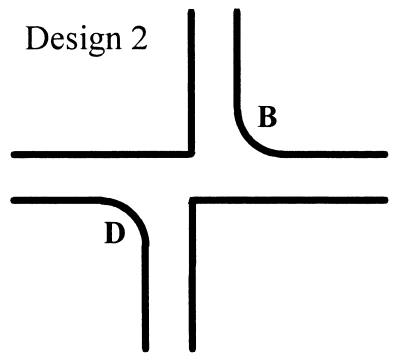

B

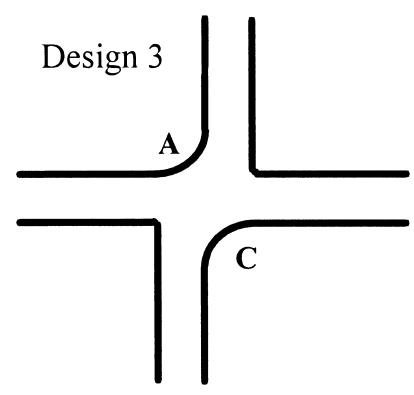

C

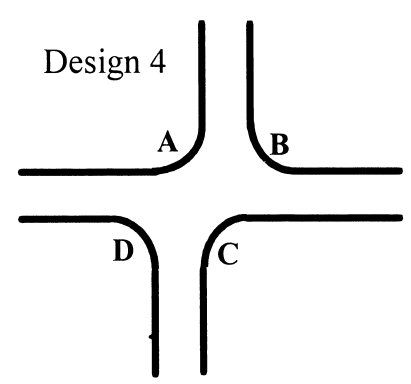

$\mathrm{D}$

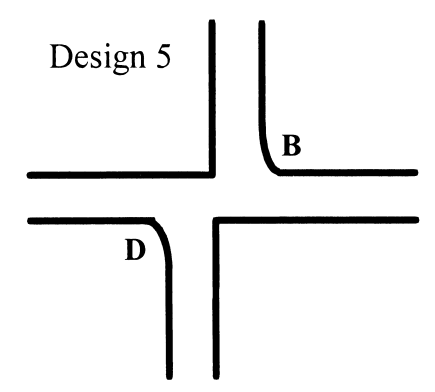

E

Fig 2. Designs 1 through 5 flared TCPC models. (A) Design 1; (B) Design 2; (C) Design 3; (D) Design 4; (E) Design 5. 
different radii of curvature), design 3 at sites $A$ and $C$, and design 4 at sites $\mathrm{A}, \mathrm{B}, \mathrm{C}$, and $\mathrm{D}$.

The $14.0-\mathrm{mm}$ inner diameter dimension of the curved and flared models was based on magnetic resonance imaging (MRI) scans performed on an 8-year-old Fontan patient.

\section{Pressure Measurements}

A constant pressure head was used to drive the steady flow loop used for these experiments. The true flow rates were measured with 3 rotometers (Dakota Instruments, Monsey, NY): one for the total caval flow rate, one for the IVC flow and the third for the RPA flow. In an effort to simulate physiologic exercise conditions, the combined caval flow rate was also fixed at $4 \mathrm{~L} / \mathrm{min}$. The SVC: IVC flow ratio was also fixed at 40:60, to reflect the flow rates seen in young children [7-9]. To simulate the variable pulmonary resistance, the RPA flow was varied from $30 \%$ of the total caval inlet flow to $70 \%$, in $10 \%$ increments. The kinematic viscosity of blood was reproduced using an aqueous solution of glycerin as the working fluid (kinematic viscosity of $\left.3.5 \times 10^{-6} \pm 1.0 \times 10^{-7} \mathrm{~m}^{2} / \mathrm{s}\right)$. Viscosity was measured using a Cannon-Fenski model 100 viscometer (Fisher Scientific, Pittsburgh, PA) and recorded throughout the experiment. Static pressure measurements were made at the center of each vessel, $10 \mathrm{~cm}$ from the connection site with blunt metal catheters inserted through 1-mm holes in each model. A multiple range pressure transducer (model DP15TL with diaphragm 3-24, Validyne Engineering Corporation, Northridge, CA) calibrated for a range of $0-15 \mathrm{mmHg}$ was used to measure the pressure within each branch in reference to the inferior vena cava. The pressure transducer was interfaced to an A/D board and pressure data were collected on a PC using a custom software package. The data were digitized at a rate of $1 \mathrm{kHz}$ over 5 seconds and averaged to produce a single mean value for static pressure.

\section{Flow Visualization}

Particle flow visualization was performed on each of the models by suspending neutrally buoyant $40 \mu \mathrm{m}$ Pliolite particles (Goodyear Chemicals, Akron, $\mathrm{OH}$ ) in the water/ glycerin solution. The model was illuminated along the centerline with a sheet of $200-W$ incandescent light to maximally visualize the flow from the motion of the particles. Using the same experimental flow system and conditions described previously for pressure measurements, video images of the flow were recorded. In addition, the particle streamlines were captured with a $35-\mathrm{mm}$ camera using a shutter speed of $1 / 30$ second, an f-stop of 5.6 and black and white ASA 400 speed film.

\section{Data Analysis}

Static pressure $\left(\mathrm{P}_{\mathrm{i}, \mathrm{s}}\right)$ measured in the center of each vessel and the volumetric flow rate $\left(Q_{i}\right)$ were used to determine the total power loss associated with each total cavopulmonary configuration. First, the dynamic pressure $\left(P_{i, k e}\right)$ was calculated from the velocity $(u)$ and density data $(p)$ using the equation:

$$
\mathrm{P}_{\mathrm{i}, \mathrm{ke}}=1 / 2 p u^{2}
$$

The velocity $(u)$ was calculated using the cross-sectional area and the volumetric flow rate measured via rotometers. Next, both the rate of kinetic and potential energy losses were calculated $\left(\mathrm{E}_{\mathrm{ke}, \text { loss }}\right.$ and $\mathrm{E}_{\mathrm{s}, \mathrm{loss}}$, respectively) using the simplified Bernoulli equation:

$$
\begin{gathered}
E_{\mathrm{ke}, \text { loss }}=\left(\mathrm{Q}_{\mathrm{ivc}} \cdot \mathrm{P}_{\mathrm{ivc}, \mathrm{ke}}+\mathrm{Q}_{\mathrm{svc}} \cdot \mathrm{P}_{\mathrm{svc}, \mathrm{ke}}\right)-\left(\mathrm{Q}_{\mathrm{rpa}} \cdot \mathrm{P}_{\mathrm{rpa}, \mathrm{ke}}+\mathrm{Q}_{\mathrm{lpa}} \cdot \mathrm{P}_{\mathrm{lpa}, \mathrm{ke}}\right) \\
\mathrm{E}_{\mathrm{s}, \mathrm{loss}}=\left(\mathrm{Q}_{\mathrm{ivc}} \cdot \mathrm{P}_{\mathrm{ivc}, \mathrm{s}}+\mathrm{Q}_{\mathrm{svc}} \cdot \mathrm{P}_{\mathrm{svc}, \mathrm{s}}\right)-\left(\mathrm{Q}_{\mathrm{rpa}} \cdot \mathrm{P}_{\mathrm{rpa}, \mathrm{s}}+\mathrm{Q}_{\mathrm{lpa}} \cdot \mathrm{P}_{\mathrm{lpa}, \mathrm{s}}\right)
\end{gathered}
$$

Total power loss (rate of energy loss) for each model was determined by summing the kinetic and potential contributions as follows:

$$
\mathrm{E}_{\text {total, loss }}=\mathrm{E}_{\mathrm{ke}, \text { loss }}+\mathrm{E}_{\mathrm{s} \text {, loss }}
$$

An average of 5000 data points were collected at each location making the use of a 2 sample $t$-test with $95 \%$ confidence valid for statistical analysis and $p$ values of less than 0.05 were considered significant.

\section{Results}

\section{Power Loss}

CURVED MODELS. Figure 3 shows the results for the curved models. The same trend can be seen in all cases. At a flow split of $70 \%$ to the RPA (right end of the graph), the power losses for all models were in the range of 4.5 to 6.5 $\mathrm{mW}$. The minimum power losses were measured when the inferior vena cava and right pulmonary artery flow rates were equal $(60 \%$ of the flow to the RPA). As this flow split to the RPA decreased, an increase in power loss was observed. In other words, as more flow was forced toward the LPA the power losses increased, reaching their maximum at $11-14.5 \mathrm{~mW}$ for a flow split of $30 \%$ to the RPA (left end of the graph). There were minor, but statistically significant $(p<0.0005)$ differences in the power losses as the degree of offset increased.

FLARED MODELS. Figure 4 summarizes the power losses versus flow split for each of the flared models. The power loss for all of the designs was lowest at the 50:50 RPA:LPA flow split and increased as this flow ratio reached both 70:30 and 30:70 ( $p<0.0005)$. The largest power losses over the complete range of flow splits were seen in design 1 (flaring on all sides with zero caval offset) and design 3 $(p<0.0005)$ (flaring at sites A and C, directing flow to the center of the connection). Design 5 (minimal flaring at sites $B$ and D, directing flow away from the connection) had significantly smaller power losses than designs 1 or 3 $(p<0.0005)$ but still had greater losses than design $2(p<$ 0.0005 ) (fully flared at sites B and D, directing flow away from the connection). Design 4, the model incorporating offset with flaring at all four anastomosis sites, had the least power losses of all flared models $(p<0.0005)$.

\section{Flow Visualization}

CURVED MODELS. Flow entering the curved TCPC site from the caval inlets was straight and undisturbed in all models. Qualitatively, the particle flow patterns recorded seemed to correlate with the observed power loss measurements and, 


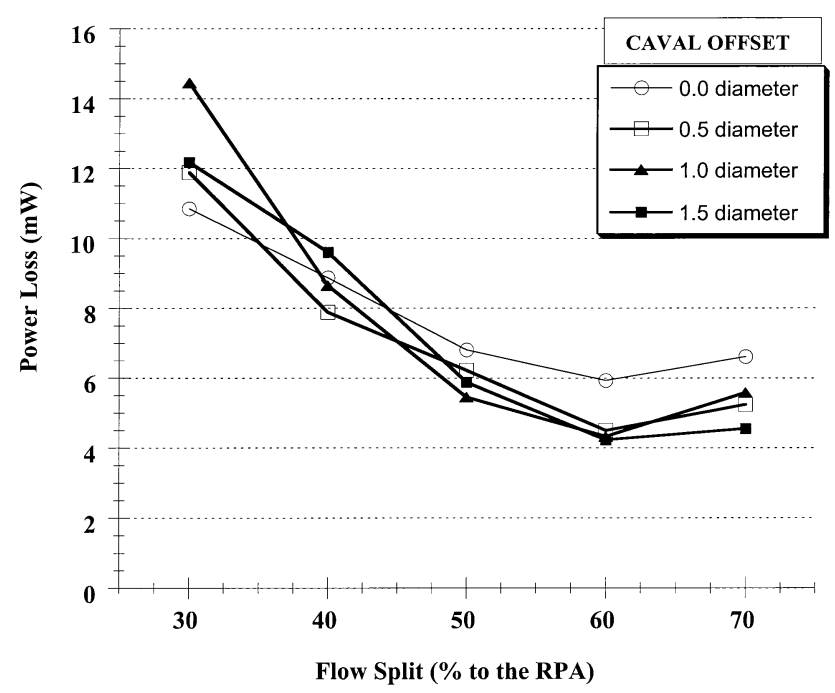

Fig 3. Power loss versus flow split to the RPA for all curved models.

in addition, they provided an explanation for the observed losses. The photographs of the curved 0.5 diameter offset model in Figures 5 and 6 show the extreme flow splits studied $(70 \%$ and $30 \%$ of the total caval inlet flow to the RPA, respectively) and are typical of all the curved offset models. As the flow split to the RPA decreased from $70 \%$ to $30 \%$, there was more direct interaction between the incoming flows from the caval inlets. As more flow from the IVC was directed counter to the curve of the IVC anastomosis (that is, toward the LPA), a region of flow separation appeared at the intersection of the IVC and the RPA. The detachment of this flow from the IVC-RPA wall resulted in a region of flow separation that significantly increased in size as the flow split to the LPA increased.

As the flow rate to the LPA increased, the fluid from the IVC was forced to turn around the sharp angle created by the curved anastomosis site. This was the origin of separation that occupied the lower wall of the LPA between the caval inlets as seen in Figure 6. When the majority of the flow exits through the RPA there is a region of recirculating fluid between the caval inlets (Fig 5). This recirculation zone appeared to be a function of the distance between caval inlets, increasing as the distance increased. As the percentage of flow to the RPA decreased, this recirculation zone between caval inlets appears to constrict the IVC inlet flow in conjunction with the separation region which develops at the IVC-RPA anastomosis (Fig 6).

The zero offset curved model had the greatest amount of flow disturbance of all the models. Strong helical flow was produced at the connection and continued as the fluid traveled along the pulmonary artery branches. This helical flow was most apparent in the zero-diameter model, but could also be detected to a less extent in the other curved offset models.

The impingement of the IVC inlet flow on the superior RPA wall was evident in all flow splits and all models (Fig 6). The location on the superior RPA wall where impingement occurred appeared to move toward the LPA as the percentage of flow to the LPA increased. The opposite was true for the

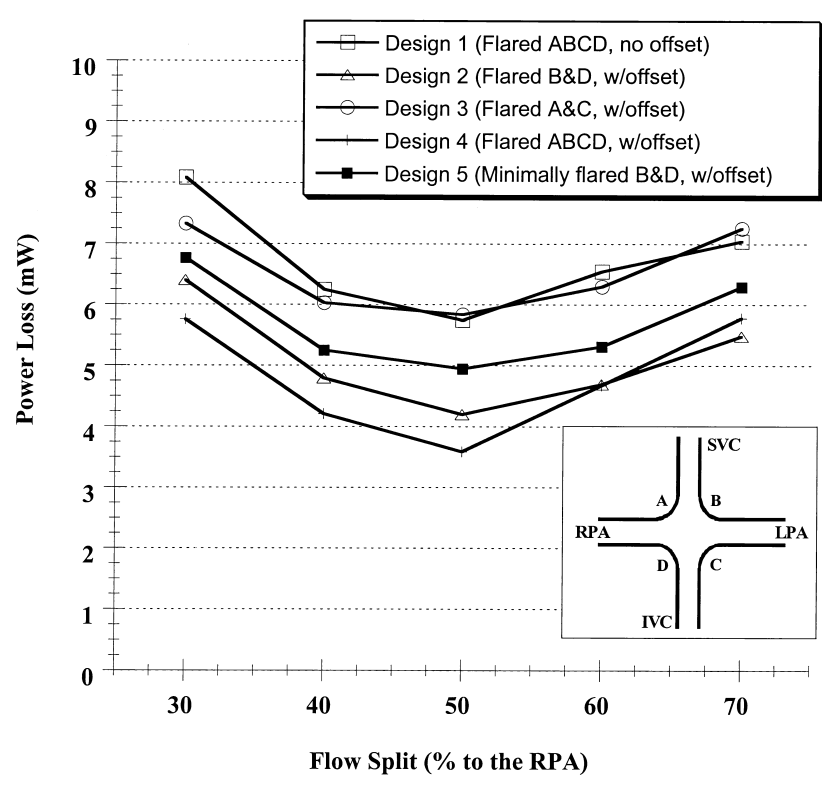

Fig 4. Power loss versus flow split to the RPA for all flared models.

impingement of the SVC flow onto the inferior wall of the LPA but it was less apparent probably because of the constantly lower SVC flow rate compared to the IVC flow rate.

FLARED MODELS. Sharma and associates [5] have previously shown that the addition of caval offset to straight models produced less disturbed flow which corresponded to lower power losses. The reduced flow disturbance and resultant decrease in power losses was also true in the flared models. Figure 7 shows the collision of caval inlets at a 50:50 flow split in flared design 1. The caval collision yielded a strong vortex in the center of the connection that switched between a clockwise and counter-clockwise rotation. This intense recirculation produced some helical flow that extended into the pulmonary arteries.

Figure 8 shows the particle streamlines with $30 \%$ of the flow toward the RPA in flared design 3. Although the flaring in this model directed caval inlets towards the

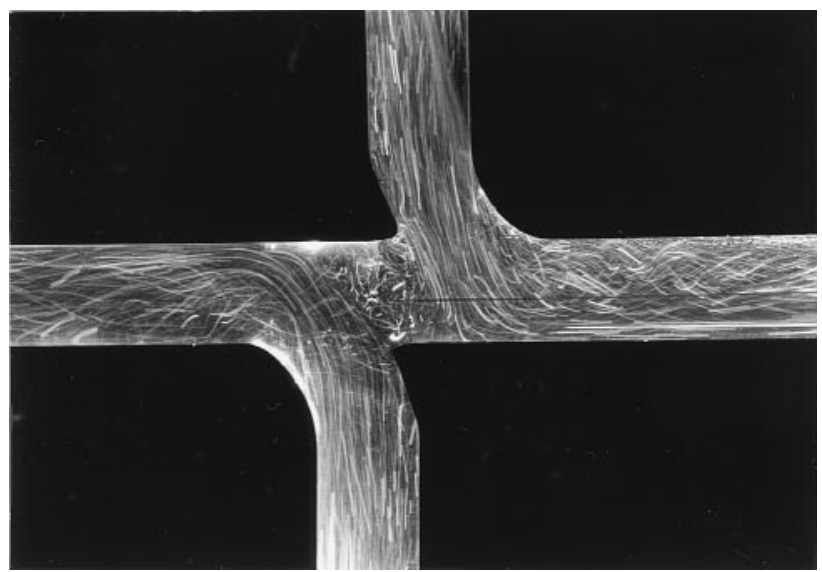

Fig 5. Particle flow visualization of a curved 0.5 diameter offset model with flow splits: IVC:SVC 60:40 and RPA:LPA 70:30. 


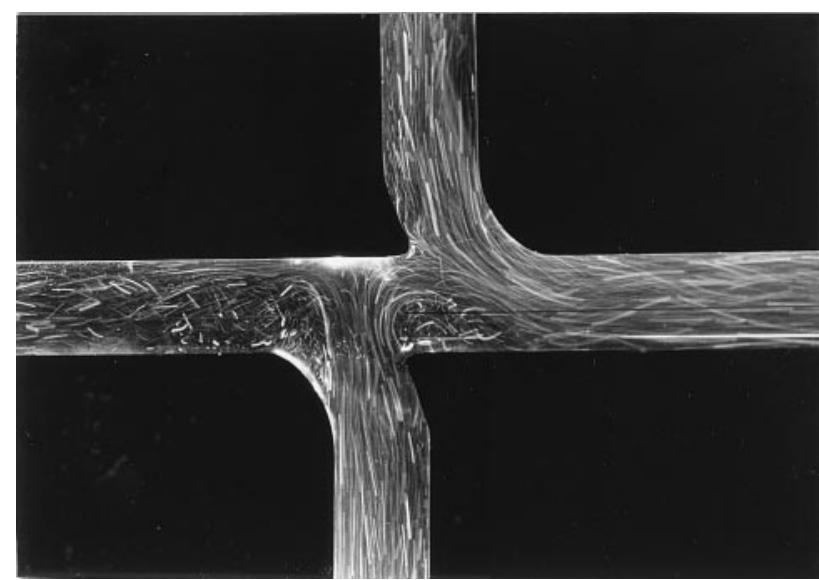

Fig 6. Particle flow visualization of a curved 0.5 diameter offset model with flow splits: IVC:SVC 60:40 and RPA:LPA 30:70.

center of the connection, the flow did not follow the flare at the IVC/LPA junction (site C). A flow separation region was established at the IVC/LPA junction and along the inferior RPA wall at the IVC/RPA $90^{\circ}$ junction (site D). Thus, the flow from the IVC impinged on the superior RPA wall and split into two streams. The point of impingement varied with varying flow splits, moving right as increasing flow was forced toward the RPA. At the RPA:LPA 70:30 flow split almost all of the flow from the IVC traveled to the RPA leaving a very large separation region at flared site $C$. The separation zone along the inferior RPA wall was largest at the RPA:LPA 30:70 flow split, and was less defined, but never disappeared as flow toward the RPA increased.

Unlike design 3 (flaring at sites A and C, directing flow to the center of the connection), the flaring in designs 2 and 5 appeared to direct the inlet caval flows away from each other avoiding direct collision of the inlet flows. Figure 9 shows design 2 at a RPA:LPA flow split 70:30. The flow patterns in designs 2 and 5 were similar to those in design 3. With respect to as more flow was forced toward the LPA, the flow from the IVC impinged on the superior RPA wall forcing it to split into two streams, flowing left and right. Conversely, at the RPA:LPA 70:30 flow split, the flow from the SVC impinged on the inferior LPA wall. Unlike design 3 , in designs 2 and 5, there was no prominent region of separation in the region between caval inlets as seen in Figure 8. While the flow from the IVC had to still divide and travel around a small separation region toward the LPA in designs 2 and 5, this flow channel from the IVC to the LPA did not encroach on the flow from the SVC nearly as much as in design 3.

The flow visualization results of flared design 4 (Fig 10), were similar to flared design 2 (Fig 9, flaring at sites B and $\mathrm{D}$, directing flow away from the connection) with respect to the effect of the IVC flow impinging on the superior wall of the RPA. In design 4, there was a small recirculation region between the caval inlets and some fluid separation at the IVC/RPA anastomosis. This separation region was greatest when $30 \%$ of flow exited the RPA, but was minimal at $70 \%$ of flow to the RPA. Unlike design 3,

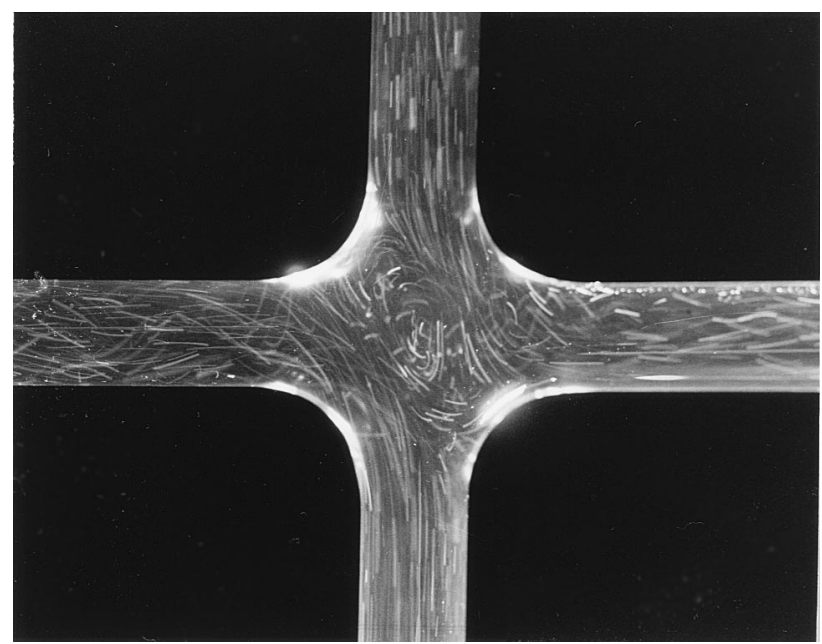

Fig 7. Particle flow visualization of flared design 1 (flaring on all sides with zero offset) model with flow splits: IVC:SVC 60:40 and RPA:LPA 50:50.

there were no obvious flow separation regions along the superior wall of the LPA distal to the connection. It also appeared that there was less restriction to SVC flow than that seen in design 3 (Fig 8).

\section{Comment}

\section{Curved Models}

The curved models were made with the inferior vena cava curved toward the right pulmonary artery and the superior cava toward the left. This explains why the power losses were lowest when the percentage of flow going to the RPA matched that entering from the IVC $(60 \%$ of the total caval flow). In this case, all of the flow from the IVC follows the natural curve of the vessel toward the RPA, and all of the flow from the SVC follows the natural curve of the vessel toward the LPA. At this flow split the power losses were comparable to those in the flared

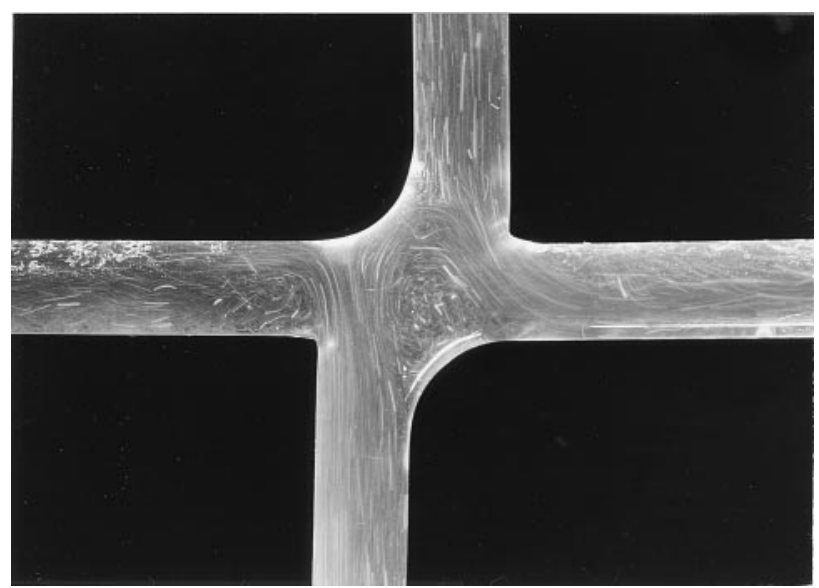

Fig 8. Particle flow visualization of flared design 3 (flaring at sites $A$ and $C$ with one diameter offset) model with flow splits: IVC: SVC 60:40 and RPA:LPA 30:70. 


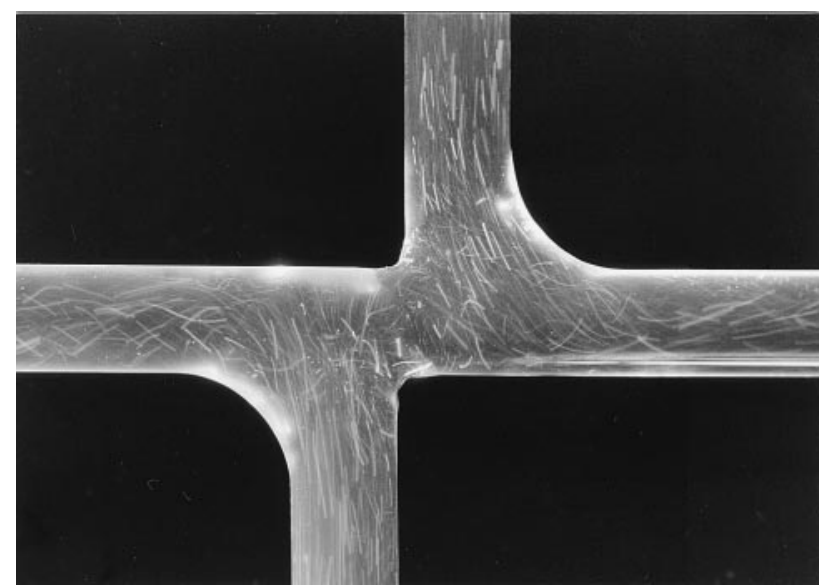

Fig 9. Particle flow visualization of flared design 2 (flaring at sites $B$ and $D$ with one diameter offset) model with flow splits: IVC:SVC 60:40 and RPA:LPA 70:30.

models 50:50 RPA:LPA flow split (4-6 mW). Based on the comparison of the power loss results with particle flow visualization, the increasing losses with decreasing RPA flow rates can be attributed to the forced collision of the incoming flows and the development of a separation region at the connection site of the IVC to both pulmonary arteries. With increasing flow to the LPA, the IVC flow was directed around an unnatural angle toward the left instead of the curved path down the RPA. The power losses in these models at RPA:LPA 30:70 are greater than the losses seen in any of the flared models at any flow split (11-14.5 $\mathrm{mW})$. This is most likely due to the turning of the flow around a sharp corner (mainly IVC to LPA and to some extent SVC to RPA) resulting in flow separation, and to the helical nature of the flow field initiated in the connection site and propelled down the pulmonary arteries. Clinically, the flow split to each pulmonary artery can not be accurately determined or predicted preoperatively. Therefore curving the vessel preferentially toward one lung can not be considered a reliable design for a range of pulmonary flow splits.

\section{Flared Models}

The flared design 1 (Fig 7) with flaring at all connection sites combined with zero offset had the greatest power losses of all flared designs studied (Fig 4). However, it had lower power losses than previous straight 90 degree models studied [5], and is still an efficient alternative. The addition of offset is an important factor for further energy conservation. This was confirmed by flow visualization, which indicated that the extra power losses in the zerooffset flared model were caused by the caval inlet collision and resulting fluid disturbance.

The model with the second largest power losses was design 3 (Fig 8), which is flared only at sites A and C. The flaring in this model directs the caval inlet flows towards the center of the anastomosis, causing a direct collision of inlet flow. Because of this geometry, the usual benefit of offset (reduced caval inlet collision) is negated and the losses resemble those measured in design 1 (flaring without offset).
In designs 2 and 5, the results showed that the larger curvature of design 2 (radius $\approx 10 \mathrm{~mm}$ ) was beneficial in hemodynamic efficiency. The flared connections in these models appear to direct the inlet caval flows away from each other avoiding significant collision of the inlet flows but still allowing adequate mixing. The introduction of flaring allowed vena caval flow to transition to the pulmonary arteries more smoothly with reduced flow restriction compared to previous straight 90 degree connections. As a result, less IVC flow encroaches into the SVC flow. The greater radius of curvature of the flare in design 2 provides a smoother flow channel for the SVC than in design 5, thus reducing the IVC to LPA and SVC flow interaction even further. The slightly larger radius of curvature explains why the power losses in design 2 (fully flared) are lower than in design 5 (minimally flared).

Design 4 had the least power loss of any of the flared designs, and would appear to incorporate the best traits of the previous 4 flared models. The flaring in this model used the greater of the two radii of curvature examined in designs 2 and 5, reducing flow restriction at the connection site. Flaring on all sides of the anastomosis provided a smooth transition of flow to the pulmonary arteries over the full range of flow splits. Flaring in addition to a 1-diameter caval offset decreased power losses by decreasing the formation of secondary flow fields and decreasing frictional (viscous) losses. This power loss reduction was also independent of pulmonary resistance. Even at the extreme flow splits (70\% and $30 \%$ to the RPA), flaring at all sites was more hemodynamically efficient than comparable models without flaring.

\section{Limitations}

This study was conducted using rigid glass models and does not address the effects of compliance on the power losses in an in vivo situation. The results for these rigid models are not expected to differ greatly from the physiologic ones. Although the nonlinear and visco-elastic properties of the vessels may have effects on the details of the local flow patterns, the local fluid dynamics will only

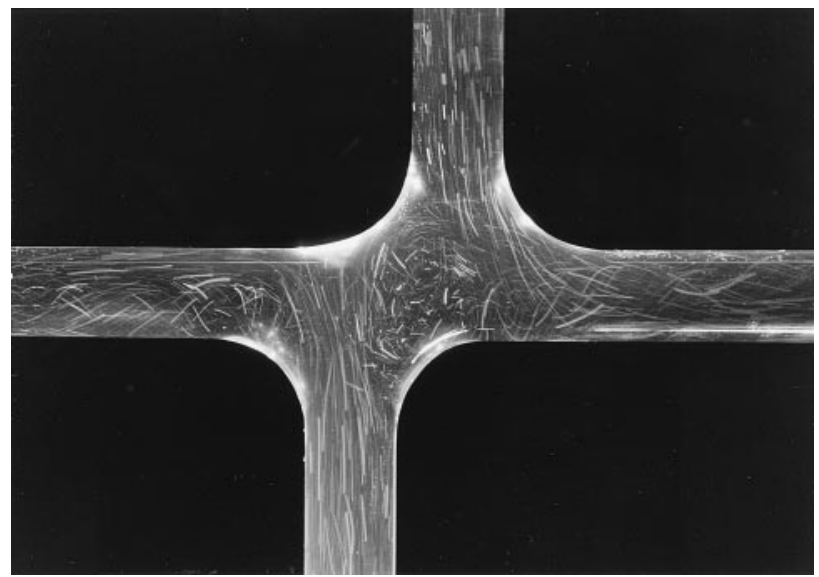

Fig 10. Particle flow visualization of flared design 4 (flaring on all sides with one diameter offset) model with flow splits: IVC:SVC 60:40 and RPA:LPA 50:50. 
be slightly affected by the wall motion because of the minimal pressure gradient in these models [10, 11].

The pulmonary flow splits in this study were adjusted by imposing resistance. The importance of this variable is to evaluate the connection geometry under a variety of possible physiologic situations (ie, variable flow to the right and left lung for a given patient). The pulmonary flow rate, not the imposed resistance was quantified and used as the variable for comparison between the different geometric connections and the resulting power loss. Careful quantification of the imposed resistance would be an interesting topic for future study.

Planar models and steady flow were used for simplicity while in vivo, the connection often incorporates superiorinferior curvature and the flow may be biphasic within the TCPC [12]. Both of these factors may contribute to TCPC hemodynamics and would be an additional consideration for further study.

Despite the experimental nature of this study, it has direct surgical significance. This study concluded that preferential curvature of the IVC toward the RPA and the SVC toward the LPA was efficient only when the flow rates from the IVC to the RPA and SVC to LPA were similar. When the flow split (ie, pulmonary resistance) prevented flow from following the natural curvatures of the vessels, excessive losses were recorded. At the RPA:LPA 30:70 flow split, power losses were an average of $56 \%$ greater for the curved models as compared to the least efficient flared model. Because of the difficulty to clinically control pulmonary resistance and the potential for this resistance to change postoperatively, preferentially curving the vessels toward one lung may be suboptimal.

Flaring at the anastomosis site reduced power losses when compared to models with preferential curving and to previous models with straight (approximately 90 degrees) connections. When compared to previous work with straight, zero caval offset models (data not shown), flaring on all sides with zero caval offset reduced losses $45 \%$. If flaring on all sides was implemented in addition to caval offset, power losses reduced $68 \%$ in comparison to the same straight model. Although this improved hemodynamic efficiency is not an absolute measure of the energy savings for a given patient, small improvements, such as those demonstrated in this study may have significant long-term effects. If the surgeon is able to flare the vessels in addition to caval offset at the cavopulmonary anastomosis, the energetic efficiency of the new connection may be significantly improved. If the anatomic space constraint limits or prohibits caval offset, flaring alone may still prove to be beneficial.

\section{References}

1. Fontan F, Baudet E. Surgical repair of tricuspid atresia. Thorax 1971;26:240-8.

2. Lins RFA, Lins MFA, Cavalcanti C, Miranda RP, Mota JH. Orthoterminal correction of congenital heart disease: double cava-pulmonary anastomosis. J Thorac Cardiovasc Surg 1982;84:633-5.

3. Laks H, Ardehali A, Grant PW, et al. Modification of the Fontan procedure: superior vena cava to left pulmonary artery connection and inferior vena cava to right pulmonary artery connection with adjustable atrial septal defect. Circulation 1995;91:2943-7.

4. Srivastava D, Preminger T, Lock JE, et al. Hepatic venous blood and the development of pulmonary arteriovenous malformations in congenital heart disease. Circulation 1995; 92:1217-22.

5. Sharma S, Goudy S, Walker P, et al. In vitro flow experiments for determination of optimal geometry of total cavopulmonary connection for surgical repair of children with functional single ventricle. J Am Coll Cardiol 1996;27:1264-9.

6. De Leval MR, Dubini G, Migliavacca F, et al. Use of computational fluid dynamics in the design of surgical procedures: application to the study of competitive flows in cavopulmonary connections. J Thorac Cardiovasc Surg 1996;111:502-13.

7. Gross G, Jonas R, Castaneda A, Hanley FL, Mayer JE, Bridges ND. Maturational and hemodynamic factors predictive of increased cyanosis after bidirectional cavopulmonary anastomosis. Am J Cardiol 1994;74:705-9.

8. Salim M, DiSessa T, Arheart K, Alpert B. Contribution of superior vena caval flow to total cardiac output in children. A Doppler echocardiographic study. Circulation 1995;92: 1860-5.

9. Geggel RL. Update on the modified Fontan procedure. Curr Opin Cardiol 1997;12:51-62.

10. Migliavacca F, de Leval MR, Dubini G, Pietrabissa R. A computational pulsatile model of the bidirectional cavopulmonary anastomosis: the influence of pulmonary forward flow. J Biomech Eng 1996;118:520-8.

11. Oddou C, Flaud P, Geiger D. Model of non-linear viscoelastic wall rheology applied to arterial dynamics. In: Bauer RD, Busse R, eds. The arterial system: dynamics, control theory, and regulation. Berlin: Springer-Verlag, 1978:101-8.

12. Rebergen SA, Ottenkamp J, Doornbos J, et al. Postoperative pulmonary flow dynamics after Fontan surgery: assessment with nuclear magnetic resonance velocity mapping. J Am Coll Cardiol 1993;21:123-31. 